Article

\title{
Fuzzy Optimization on the Synthesis of Chitosan-Graft-Polyacrylic Acid with Montmorillonite as Filler Material: A Case Study
}

\author{
Angelo Earvin Sy Choi ${ }^{1,+}$, Cybelle Morales Futalan ${ }^{1,+}+$ (i) and Jurng-Jae Yee ${ }^{2, *}$ \\ 1 National Research Center for Disaster-Free and Safe Ocean City, Busan 49315, Republic of Korea; \\ angelochoi2003@yahoo.com (A.E.S.C.); cmfutalan@gmail.com (C.M.F.) \\ 2 Department of Architectural Engineering, Dong-A University, Busan 49315, Korea \\ * Correspondence: jjyee@dau.ac.kr; Tel.: +82-51-200-7609; Fax: +82-51-294-2256 \\ + Co-first authors.
}

Received: 8 April 2019; Accepted: 21 April 2019; Published: 23 April 2019

\begin{abstract}
In this paper, the synthesis of a chitosan-montmorillonite nanocomposite material grafted with acrylic acid is presented based on its function in a case study analysis. Fuzzy optimization is used for a multi-criteria decision analysis to determine the best desirable swelling capacity $\left(Y_{Q}\right)$ of the material synthesis at its lowest possible variable cost. For $Y_{Q}$, the integrating the result's cumulative uncertainty is an essential element to investigate the feasibility of the developed model equation. The Pareto set analysis is able to set the appropriate boundary limits for $Y_{Q}$ and the variable cost. Two case studies are presented in determining the lowest possible cost: Case 1 for maximum $Y_{Q}$, and Case 2 for minimum $Y_{Q}$. These boundary limits were used in the fuzzy optimization to determine its global optimum results that achieved the overall satisfaction ratings of $67.2 \%$ (Case 1 ) and $52.3 \%$ (Case 2). The synthesis of the polyacrylic acid/chitosan material for Case 1 resulted in $305 \mathrm{~g} / \mathrm{g} Y_{Q}$ and $10.8 \mathrm{USD} / \mathrm{kg}$, while Case 2 resulted in $97 \mathrm{~g} / \mathrm{g} Y_{Q}$ and $12.3 \mathrm{USD} / \mathrm{kg}$. Thus, the fuzzy optimization approach proves to be a practical method for examining the best possible compromise solution based on the desired function to adequately synthesize a material.
\end{abstract}

Keywords: ammonium persulfate; fuzzy optimization; $N, N^{\prime}$-methylenebisacrylamide; Pareto set; polyacrylic acid; swelling capacity; variable cost

\section{Introduction}

Superabsorbents are smart, functional materials composed of lightly crosslinked hydrophilic polymers with the capacity to hold a large quantity of aqueous and biological fluids even at extreme pressure [1]. It also has the capability to release the collected fluids under a dry environment [2]. Superabsorbents are characterized by their high swelling capacities where saline fluids and water are retained up to 100-1000 times their original dry weight without losing their structural framework and integrity [3]. The preparative methods for superabsorbents involve the attachment of various functional groups such as amide, amine, hydroxyl, sulfonic acid, and carboxylic acid onto the polymer network [4]. Excellent properties of superabsorbents include elasticity, hydrophilicity, high swelling rate, porosity, softness and biodegradability [5-7]. Superabsorbents are classified into three groups: synthetic (derived from petroleum products), natural, and hybrid (vinyl monomers grafted onto natural polymers) [8]. However, petroleum-based polymers have limited utilization due to poor degradability, costly to produce, and toxicity with detrimental impacts to human health and the environment $[9,10]$.

Natural polysaccharides including cashew gum, pectin, chitin, alginate, cellulose, starch, and chitosan $(\mathrm{Ch})$ have gained attention due to their renewability, abundance, biocompatibility, biodegradability, environment-friendliness, and inexpensiveness [11,12]. $\mathrm{Ch}$, which is an amino 
polysaccharide of high molecular weight and crystalline structure, is produced via alkaline deacetylation of chitin that is derived from exoskeletons of krills, lobsters, shrimps, crabs and crawfish. It is composed of binary linear units of $(1 \rightarrow 4)-2$-amino-2-deoxy- $\beta$-D-glucan and $(1 \rightarrow 4)$-2-acetamido-2-deoxy- $\beta$-D-glucan $[1,13,14]$. There are numerous remarkable characteristics of Ch including low-cost, chelating capacity, availability, anti-microbial activity, biodegradability, low immunogenicity and being environmentally benign [15]. However, pure $\mathrm{Ch}$ is known for its low specific gravity and poor mechanical integrity [16]. Graft copolymerization of vinyl monomers, which contain hydrophilic side groups, onto the Ch backbone has been known to enhance the biodegradability, $\mathrm{pH}$ resistance, thermal stability, water absorptive capability, and salt tolerance as well as minimize the need for oil-based monomers $[1,17,18]$. Acrylic acid (AA) as vinyl monomer has been extensively studied due to its decreased cytotoxicity and improved biocompatibility [19]. However, composite materials derived from natural polymers grafted with vinyl monomers suffer due to their high manufacturing cost and reduced mechanical strength [20].

Recently, incorporation of inorganic fillers such as clay minerals has yielded organic/inorganic composites with improved stiffness and strength, lower cost of production, better handling, enhanced swelling ability, and satisfactory adsorption performance [13,20-23]. Montmorillonite (Mt), which is a member of the smectite group, is comprised of a 2:1 ratio of silica tetrahedron and alumina octahedral sheets [24]. The formula of $\mathrm{Mt}$ is $(\mathrm{Na}, \mathrm{Ca})_{0.33}(\mathrm{Al}, \mathrm{Mg})_{2}\left(\mathrm{Si}_{4} \mathrm{O}_{10}\right)(\mathrm{OH})_{2} \cdot n \mathrm{H}_{2} \mathrm{O}$, where it is described as a soft layered silicate with high cation exchange capacity, small particle diameter, and excellent aspect ratio and plane strength $[25,26]$.

In the previous work of Abdel Aziz and Salama [27], Ch-graft-polyacrylic acid (ChPA) with Mt as filler material was prepared as a superabsorbent. The results showed the disappearance of $\mathrm{d}_{001}$ peak at $2 \theta=6.6^{\circ}$ after polymerization. This implies exfoliation of vinyl-modified Mt into individual nanolayers has occurred $[27,28]$. The maximum equilibrium swelling was determined via optimization study using response surface methodology (RSM) with Box-Behnken Design (BBD). The following optimal conditions were determined: $2.98 \mathrm{wt} \%$. initiator, $1.04 \mathrm{wt} \%$ crosslinker and $9.76 \mathrm{AA} / \mathrm{Ch}$ molar ratio [27]. RSM is comprised of statistical and numerical methods utilized in the optimization of multiple factor levels in material preparation and treatment technologies [29,30]. The relationship between process variables and their responses are evaluated where an empirical polynomial model is fitted [31]. RSM also help recognize which of the main variables and their interactions significantly affect the process. However, there are no studies reported on the fuzzy logic technique in the field of material synthesis for superabsorbents. In literature, there is no information that utilized the fuzzy logic system to investigate the cumulative uncertainty error and variable cost on the preparation of superabsorbent.

The fuzzy logic method is a precise modeling tool employed in the evaluation, mapping, modeling, and prediction in areas of environment and ecology [32]. Fuzzy logic allows adaptability of models with a degree of uncertainty near the boundary of unsuitable and suitable areas. The fuzzy system applies sigmoidal adjustment (Gaussian, linear or other method) to adequately define the system's behavior for criteria parameterization [33]. Fuzzy logic system is less likely to be influenced by the analyst's opinion where an acceptable model is defined by the minimum and maximum values of the variables [34].

The present work uses multi-objective optimization with the fuzzy logic concept in the selection of the optimum condition for the synthesis of Ch-Mt composites grafted with PA (ChPA-Mt). The global optimum solution that would yield the best swelling capacity of ChPA-Mt and provide the lowest possible variable cost was determined. The effect of AA/Ch molar ratio, ammonium persulphate as initiator and $N, N^{\prime}$-methylenebisacrylamide as crosslinker on the total variable cost and swelling capacity with respect to the synthesis of ChPA-Mt was investigated.

Using the fuzzy optimization approach, the selection of the ideal swelling capacity was dependent on the end-use (absorbent/adsorbent) of the material. Two cases were considered in the present work where the first case determined the appropriate condition to synthesize an absorbent that would yield 
the maximum swelling capacity for the least variable cost. The second case evaluated the synthesis of an adsorbent where minimal swelling capacity is preferred at the least possible cost. Superabsorbents have been utilized as an adsorbent in the removal of crystal violet dye [35], napthol green dye [35], sunset yellow dye [35], anionic dye [36], $\mathrm{Cu}^{2+}[37], \mathrm{Co}^{2+}$ [37], $\mathrm{Ni}^{2+}$ [37], and $\mathrm{Cd}^{2+}$ [37] from wastewater. Adsorption technology involving industrial fixed-bed reactors requires adsorbent material to have the least swelling capacity to avoid fouling and clogging of the reactor [38].

\section{Methodology}

\subsection{Materials}

Acetic acid, Ch (90\% deacetylation degree), Mt, N,N'-methylenebisacrylamide, ammonium persulphate, and AA were acquired from Sigma-Aldrich (WI, USA). The preparative method utilized for $\mathrm{N}$-octyl- $\mathrm{N}$-vinyl-2-pyrrolidonium bromide was based on previous work by Naguib et al. [39].

\subsection{Experimental Method}

Approximately $50 \mathrm{~mL}$ of acetic acid (1\% v/v) was used to dissolve $2 \mathrm{~g} \mathrm{Ch}$, and the solution was purged for $40 \mathrm{~min}$ using $\mathrm{N}_{2}$ gas. The solution was added to a pre-determined amount of ammonium persulphate, after which AA and $N, N^{\prime}$-methylenebisacrylamide were also added to the mixture. Then, mixture was allowed to react for $4 \mathrm{~h}$ at $70^{\circ} \mathrm{C}$. The final solution was allowed to cool, and was then neutralized with $1 \mathrm{M} \mathrm{NaOH}$ until a pH of 7.0 was attained. The ChPA-Mt material was washed with water to remove any impurities and dried in an oven at $70^{\circ} \mathrm{C}$. Unreacted AA and PA were removed using ethanol in a Soxhlet extractor for $24 \mathrm{~h}$, ensuring that only crosslinked copolymer was attained.

\subsection{Fuzzy Multi-Objective Optimization Method}

The most probable parametric conditions of the variable cost and the total swelling capacity in account of its cumulative uncertainty of results was attained by applying the Pareto set analysis and fuzzy mathematical programming in the optimization studies. For the process parameters (vinylic monomer/biopolymer molar ratio, crosslinker and initiator) of the synthesis of a ChPA-Mt material, the process parameters and the material costs are listed in Table 1. Moreover, Table 2 shows the data derived from the study of Abdel Aziz and Salama [27] with the additional incorporation of the cumulative uncertainty of results. A linguistic value that applies the true value theory, ranging from completely false (0) to completely true (1), was utilized to estimate the reasoning approach in the fuzzy optimization analysis [40]. Figure 1 illustrates the algorithm flowchart of the fuzzy system in the present work. Optimization studies were performed using Lingo 18.0 (Lindo Systems, Chicago, IL, USA) where non-linear programming software uses a global optimizer.

Table 1. (a) Variables and (b) costing parameters for the synthesis of the clay-polymer composite material.

\begin{tabular}{ccc}
\hline (a) Process Parameters & Unit & Range \\
\hline AA/Ch $(A)$ & & $5-10$ \\
$N, N^{\prime}$-methylenebisacrylamide $(B)$ & wt $\%$ & $1-3$ \\
Ammonium persulfate $(C)$ & wt $\%$ & $1-3$ \\
\hline (b) Chemicals & Unit & $*$ Material Cost \\
\hline AA & USD $/ g$ & 0.44 \\
$N, N^{\prime}$-methylenebisacrylamide & USD $/ g$ & 0.41 \\
Ammonium persulfate & USD $/ g$ & 0.39 \\
\hline *Sigma Aldrich (WI, USA); AA: acrylic acid; Ch: chitosan.
\end{tabular}

* Sigma Aldrich (WI, USA); AA: acrylic acid; Ch: chitosan. 


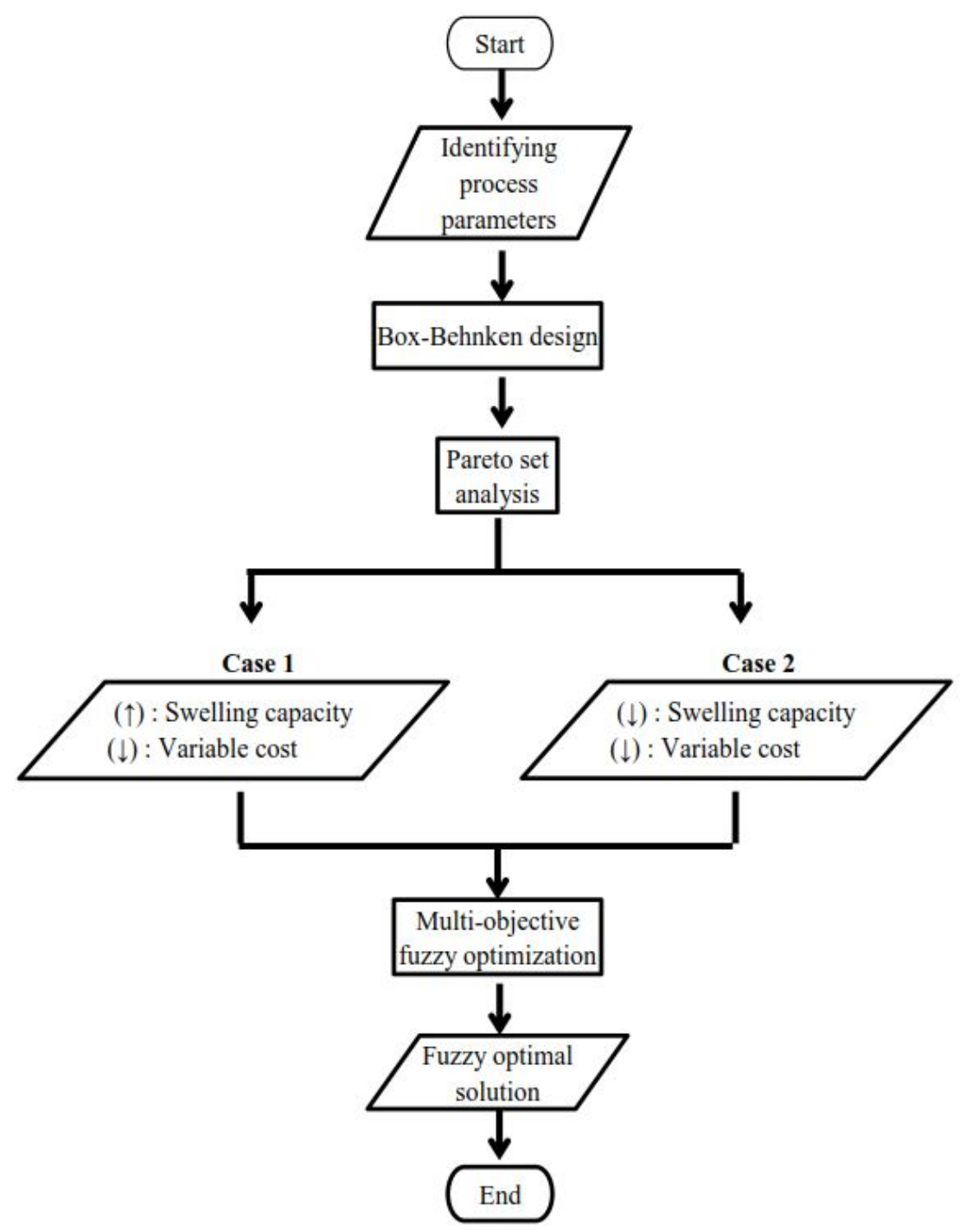

Figure 1. Fuzzy optimization process diagram.

Table 2. Clay-polymer composite material synthesis based on the BBD matrix.

\begin{tabular}{|c|c|c|c|c|c|}
\hline Run & $\begin{array}{l}\mathrm{AA} / \mathrm{Ch} \\
\quad(A)\end{array}$ & $\begin{array}{c}N, N^{\prime} \text {-methylenebisacrylamide } \\
(B: \text { wt \%) }\end{array}$ & $\begin{array}{c}\text { Ammonium } \\
\text { Persulfate }(C: \text { wt \%) }\end{array}$ & $\begin{array}{l}\text { Predicted Swelling } \\
\text { Capacity }(\mathrm{g} / \mathrm{g})\end{array}$ & $\begin{array}{c}\text { * Cumulative } \\
\text { Uncertainty }(\mathrm{g} / \mathrm{g})\end{array}$ \\
\hline 1 & 5 & 2 & 1 & 74 & 19 \\
\hline 2 & 5 & 3 & 2 & 66 & 14 \\
\hline 3 & 5 & 1 & 2 & 232 & 17 \\
\hline 4 & 5 & 2 & 3 & 164 & 14 \\
\hline 5 & 7.5 & 3 & 3 & 192 & 9 \\
\hline 6 & 7.5 & 2 & 2 & 220 & 13 \\
\hline 7 & 7.5 & 2 & 2 & 220 & 13 \\
\hline 8 & 7.5 & 3 & 1 & 91 & 17 \\
\hline 9 & 7.5 & 2 & 2 & 220 & 13 \\
\hline 10 & 7.5 & 1 & 3 & 322 & 13 \\
\hline 11 & 7.5 & 1 & 1 & 221 & 19 \\
\hline 12 & 7.5 & 2 & 2 & 220 & 13 \\
\hline 13 & 7.5 & 2 & 2 & 220 & 13 \\
\hline 14 & 10 & 3 & 2 & 226 & 10 \\
\hline 15 & 10 & 2 & 1 & 186 & 17 \\
\hline 16 & 10 & 1 & 2 & 320 & 13 \\
\hline 17 & 10 & 2 & 3 & 299 & 8 \\
\hline
\end{tabular}

Adapted from Abdel Aziz and Salama [27]; * calculated cumulative uncertainty of the results; BBD: Box-Behnken design. 


\subsubsection{Determination of Boundary Limits through the Pareto Optimality}

The process of choosing an exact number of courses that would generate a substantial overall effect for numerous competing practical solutions was carried out using the Pareto analysis [41]. The initial Pareto optimum solution under several weights of the objective function was obtained using the Pareto set process [42]. Initially, the boundary limits for variable cost and swelling capacity were attained using the method. The multi-objective fuzzy optimization applied the boundary limits. The first objective function in Equation (1) pertains to the swelling capacity in consideration of its uncertainty error $\left(Y_{Q}: \mathrm{g} / \mathrm{g}\right)$. This is either to maximize or minimize depending on desired condition of the case study in the synthesis of the polymer clay nanocomposite material. For $Y_{Q}$ at its maximum value, the upper limits of $Y_{Q}$ and total variable $\operatorname{cost}\left(V C_{T}\right.$ : USD $\left./ \mathrm{kg}\right)$ were determined. The lower boundary limits of $Y_{Q}$ and $V C_{T}$ were determined through minimizing the second objective function in Equation (2). In the case of determining the minimum value of $Y_{Q}$, this was able to draw out the lower and upper limits of $Y_{Q}$ and $V C_{T}$, respectively, while its upper and lower boundaries were determined through Equation (2).

Objective functions:

$$
\begin{gathered}
\max / \min Y_{Q} \\
\min V C_{T}
\end{gathered}
$$

In order to satisfy the objective functions, the constraints were subjected to Equations (3)-(7). The sum of the swelling capacity $(Y: g / g)$ and its corresponding uncertainty error $\left(W_{Y}: g / g\right)$ are shown in Equation (3). The response for the model equation in Equation (4) pertains to the swelling capacity of the synthesized polymer clay nanocomposite material. The incorporation of the constraints of the cumulative uncertainty of the response for the swelling capacity and the total variable cost are shown in Equations (5) and (6), respectively. Equation (7) pertains to the feasible regions of the variables tested based on the vinylic monomer/biopolymer molar ratio, crosslinker and initiator.

Constraints:

$$
\begin{gathered}
Y_{Q}=Y+W_{Y} \\
Y=\beta_{0}+\sum_{i=1}^{n} \beta_{i} X_{i}+\sum_{i=1}^{n-1} \sum_{i=1}^{n} \beta_{i j} X_{i} X_{j}+\sum_{i=1}^{n} \beta_{i i} X_{i}^{2} \\
W_{Y}=\left(\sum_{i=n}^{n} \frac{\partial Y}{\partial X_{i}} W_{X_{i}}\right)^{\frac{1}{2}} \\
V C_{T}=\sum_{i=1}^{n} V C_{i} \\
X_{i}^{L} \leq X_{i} \leq X_{i}^{U}
\end{gathered}
$$

where $\beta_{0}$ pertains to the constant; $i$ and $j$ are the single and interacting factor indices, respectively; $n$ denotes the tested number of variables; $\beta_{i}, \beta_{i j}$. and $\beta_{i i}$ are the regression coefficients; $X_{i}$ and $X_{j}$ are the independent variables; $W_{X}$. and $V C$ are the variable uncertainty and variable cost, respectively; while $L$ and $U$ represent the lower and upper boundary limit, respectively.

\subsubsection{Multi-Objective Decision Making through Fuzzy Logic}

The identification of the best solution derived from the recognized set of Pareto optimal conditions would require the utilization of a multi-criteria analysis [42]. The fuzzy mathematical programming system was employed to arrive at a solution from a multi-objective decision-making problem [43-45]. The perception of max-min aggregation that would concurrently enhance the satisfaction degree would be employed to maximize the overall satisfaction degree for the objective function [43-48]. Moreover, 
the degree of satisfaction for overall swelling capacity and the total variable cost of the results must satisfy the overall satisfaction as presented in Equation (8).

Objective function:

$$
\max \mu_{O} \leq \mu_{S C} \text { and } \mu_{V C}
$$

where $\mu_{S C}$ and $\mu_{V C}$ are the individual level of satisfaction of the overall swelling capacity and the total variable cost, respectively.

The constraints used to attain the fuzzy goal are given in Equations (9)-(12). The linear membership function depending on the desired function in either maximizing or minimizing the swelling capacity for the polymer clay nanocomposite material are shown in Equations (9) and (10), respectively. Equation (11) refers to the linear membership function for minimizing the total variable cost involved in the material synthesis. Moreover, the level of satisfaction has a limiting constraint that could only be adjusted within a feasible range as described in Equation (12).

Constraints:

$$
\begin{gathered}
\mu_{S C}=\frac{Y_{Q}-Y_{Q}^{L}}{Y_{Q}^{U}-Y_{Q}^{L}} \\
\mu_{S C}=\frac{Y_{Q}^{U}-Y_{Q}}{Y_{Q}^{U}-Y_{Q}^{L}} \\
\mu_{V C}=\frac{V C_{T}^{U}-V C_{T}}{V C_{T}^{U}-V C_{T}{ }^{L}} \\
\mu_{O}^{L} \leq \mu_{O} \leq \mu_{O}^{U}
\end{gathered}
$$

\section{Results and Discussion}

\subsection{Effect of AA/Ch Molar Ratio on the Swelling Capacity and Its Variable Cost}

In order to investigate the influence of AA/Ch molar ratio on the material synthesis, the amount of $N, N^{\prime}$-methylenebisacrylamide and ammonium persulfate were individually kept constant at $2 \mathrm{wt} \%$. The identification of a proper ratio between the vinylic monomer and biopolymer is essential to avoid the competition with AA led to its auto-polymerization aside from the grafting of the Ch material [49]. Figure $2 \mathrm{a}$ illustrates the effect of $\mathrm{AA} / \mathrm{Ch}$ molar ratio towards the swelling capacity and variable cost.

The trend of the molar ratio from 5 to 10 resulted in a swelling capacity from $141 \pm 15 \mathrm{~g} / \mathrm{g}$ to $264 \pm 11 \mathrm{~g} / \mathrm{g}$, respectively. It was observed that a higher AA concentration leads to a larger swelling capacity upon the synthesis of the polymer clay nanocomposite material. An electrostatic repulsion and ionization in the chain takes place at a higher ratio due to the promotion of available carboxylic groups that is able to expand the originally coiled molecules [50].

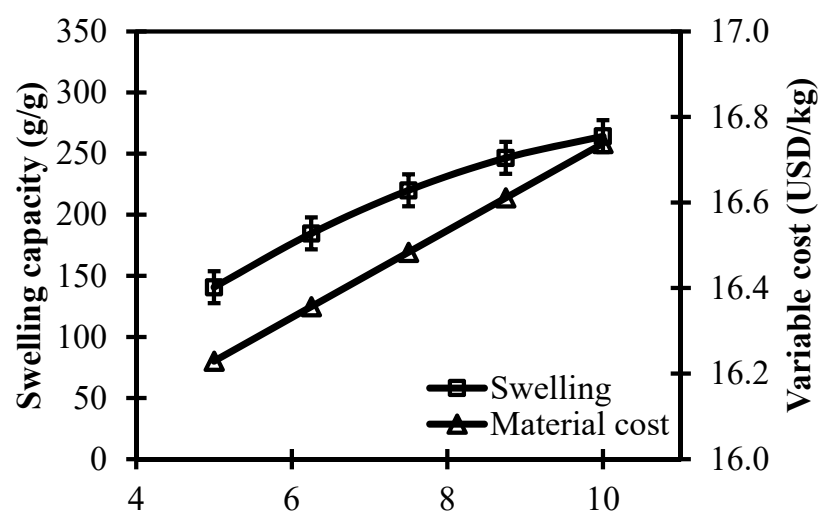

(a) Acrylic acid/Chitosan ( $\mathrm{mol} / \mathrm{mol})$

Figure 2. Cont. 


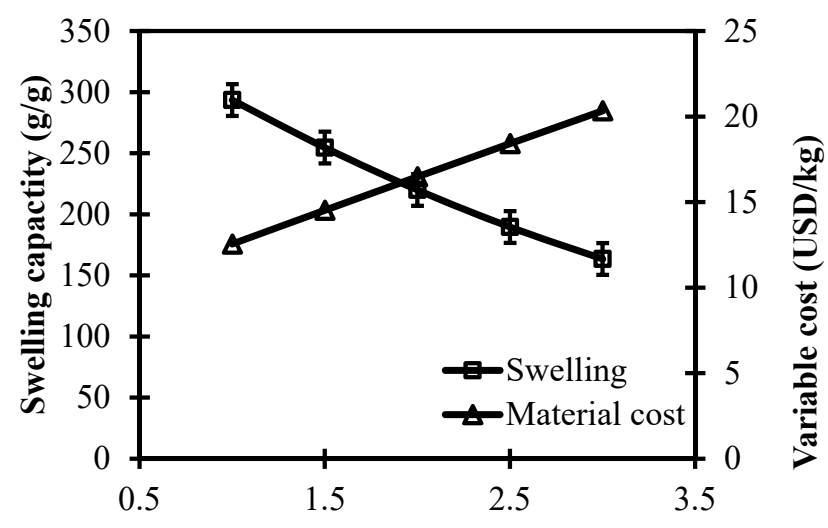

(b) $\quad \mathrm{N}, \mathrm{N}^{\prime}$-methylenebisacrylamide (wt\%)

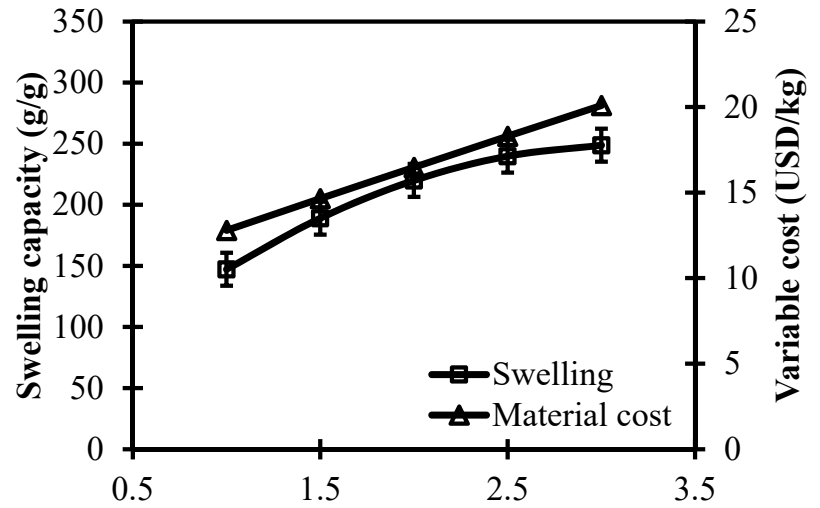

(c) Ammonium persulfate (wt\%)

Figure 2. Simultaneous analysis of swelling capacity and variable cost at different levels of (a) acrylic acid/chitosan, (b) $N, N^{\prime}$-methylenebisacrylamide, and (c) ammonium persulfate.

In the aspect of the incurred total variable cost, the material synthesis at incremental molar ratio from 5 to 10 showed higher variable cost from $16.2 \mathrm{USD} / \mathrm{kg}$ to $16.7 \mathrm{USD} / \mathrm{kg}$. This is due to a higher AA loading that is utilized to synthesize the polymer clay nanocomposite material. Aside from achieving the desirable swelling capacity, it is also essentially important to minimize the variable cost to achieve an efficient and cheap material according to its function.

\subsection{Effect of $N, N^{\prime}$-methylenebisacrylamide on the Swelling Capacity and Its Variable Cost}

$N, N^{\prime}$-methylenebisacrylamide is used as the crosslinker for the polymer clay nanocomposite material synthesis. Crosslinking is favorable due to its capacity to improve chemical stability and mechanical strength [51]. To determine the effect of the amount of $N, N^{\prime}$-methylenebisacrylamide on the resulting material, the AA/Ch molar ratio of 7.5 and ammonium persulfate content of $2 \mathrm{wt} \%$ were kept constant throughout the variation of the crosslinker dosage. The detailed response of the swelling capacity and variable cost at different $N, N^{\prime}$-methylenebisacrylamide concentration are depicted in Figure $2 b$.

At $1 \mathrm{wt} \% N, N^{\prime}$-methylenebisacrylamide, a swelling capacity of $294 \pm 15 \mathrm{~g} / \mathrm{g}$ was synthesized. Increasing the crosslinker content further to $3 \mathrm{wt} \%$ was able to lower the swelling capacity to $164 \pm 12 \mathrm{~g} / \mathrm{g}$. A higher crosslinker concentration was attributed to the decreasing polymer chain relaxation that led to less swelling [50]. Furthermore, large quantities of crosslinker content increased the crosslink density that tended to restrict additional free volume from being utilized [52].

For the trend from $1 \mathrm{wt} \%$ to $3 \mathrm{wt} \%$ of $N, N^{\prime}$-methylenebisacrylamide, the swelling capacity decreased while variable cost increased. The inverse relationship of the resulting material and its cost proved to be one of the essential criteria for achieving an efficient outcome for its synthesis. Higher 
$N, N^{\prime}$-methylenebisacrylamide implies more material usage that increases the specified variable cost the specified parameter. After selecting the appropriate combination of the crosslinker dosage, the resulting polymer clay nanocomposite material could be utilized in various applications due to its ability to form macromolecular structures [51].

\subsection{Effect of Ammonium Persulfate on the Swelling Capacity and Its Variable Cost}

The use of chemical initiators is essential for its function in generating living free radicals that enable the initiation of polymerization reactions in vinyl monomers [53]. Ammonium persulfate is used as the initiator in the graft polymerization of the AA onto $\mathrm{Ch}$. To determine the effects of ammonium persulfate, the AA/Ch molar ratio and $N, N^{\prime}$-methylenebisacrylamide dosage were kept constant at 7.5 and $2 \mathrm{wt} \%$, respectively. Figure 2c shows the results of the variation of ammonium persulfate on the swelling capacity and variable cost.

The results exhibited increasing swelling capacity from $147 \mathrm{~g} / \mathrm{g}$ to $249 \mathrm{~g} / \mathrm{g}$ at the corresponding ammonium persulfate dosages from $1 \mathrm{wt} \%$ to $3 \mathrm{wt} \%$. In terms of the pore distribution, a higher initiator content provides additional free volume that allows higher water mobility leading to a higher swelling degree [52]. Furthermore, an increase in the initiator concentration is able to promote the formation of polymer chain ends in the network leading to higher swelling activities [54].

Aside from the crosslinker, the use of the initiator also contributes to a high production cost in the synthesis of the polymer clay nanocomposite material [49]. The variable cost increased from 12.8 USD $/ \mathrm{kg}$ to $20.1 \mathrm{USD} / \mathrm{kg}$ when ammonium persulfate was changed from $1 \mathrm{wt} \%$ to $3 \mathrm{wt} \%$. Higher initiator content increased the material loading that mainly contributed to a larger variable cost. Thus, this is an essential factor for consideration to achieve optimal results upon determining the best compromise solution in a low-cost material synthesis at its ideal swelling capacity.

\subsection{Pareto Set Result}

The Pareto set analysis determined the appropriate upper and lower boundary limits of the swelling capacity with its cumulative uncertainty error and the total variable cost of the polymer clay nanocomposite material. The BBD under the response surface methodology was utilized as the basis to draw out the Pareto efficiency upon the grafting of AA onto $\mathrm{Ch}$. The results of the analysis would then be essentially used towards the preference criterion in the latter part of the decision-making analysis. In the material synthesis of the two case studies, a non-linear model equation is used for the response of the swelling capacity. This type of equation often leads to multiple local optimums and the global optimum are not directly given [55]. The global optimal solution is favorable to carry out the best possible solution in a given set of constraints for the objective function. Thus, the global optimizer option in the Lingo software is utilized to be able to achieve the best resulting solution for synthesis.

The Pareto analysis generates a Ch-graft-PA material through the application of Equations (13)-(27). Equation (13) shows the generated and validated model equation adapted from the study of Abdel Aziz and Salama [27] that describes the swelling capacity of the produced polymer clay nanocomposite material. The cumulative uncertainty of the response in Equation (14) indicates the possible error associated with the synthesis step towards the desired value of the swelling capacity. This is specifically determined through the partial derivatives with respect to AA/Ch molar ratio (Equation (15)), $N, N^{\prime}$-methylenebisacrylamide concentration (Equation (16)), and ammonium persulfate concentration (Equation (17)). The integration of the incurred total variable cost in Equation (18) is a key parameter in the Pareto optimal analysis. Specifically, the individual variable cost of $\mathrm{AA}, N, N^{\prime}$-methylenebisacrylamide and ammonium persulfate are shown in Equations (19)-(21), while its calculated material usage are presented in Equations (22)-(24), respectively. Furthermore, Equations (25)-(27) are the boundary limits that denote the respective variables of AA, $N, N^{\prime}$-methylenebisacrylamide and ammonium persulfate.

$$
Y=-7.25+47.9 X_{1}-153 X_{2}+122.25 X_{3}+7.2 X_{1} X_{2}+2.2 X_{1} X_{3}-2.8 X_{1} X_{1}+8.5 X_{2} X_{2}-22 X_{3} X_{3}
$$




$$
\begin{aligned}
W_{Y}=\sqrt{\left(\frac{\partial Y_{Q}}{\partial X_{1}} W_{X_{1}}\right)^{2}+\left(\frac{\partial Y_{Q}}{\partial X_{2}} W_{X_{2}}\right)^{2}+\left(\frac{\partial Y_{Q}}{\partial X_{3}} W_{X_{3}}\right)^{2}} \\
\frac{\partial Y}{\partial X_{1}}=47.9+7.2 X_{2}+2.2 X_{3}-5.6 X_{1} \\
\frac{\partial Y}{\partial X_{2}}=-153+7.2 X_{1}+17 X_{2} \\
\frac{\partial Y}{\partial X_{3}}=122.25+2.2 X_{1}-44 X_{3} \\
V C_{T}=V C_{1}+V C_{2}+V C_{3} \\
V C_{1}=\frac{442.42 A}{(A+I+C+2)} \\
V C_{2}=\frac{421.43 I}{(A+I+C+2)} \\
V C_{3}=\frac{395.96 C}{(A+I+C+2)} \\
A=4.804 x 10^{-4} X_{1} \\
I=\frac{(A+2) X_{2}}{100} \\
C=\frac{(A+2) X_{3}}{100} \\
5 \leq X_{1} \leq 10 \\
1 \leq X_{2} \leq 3 \\
1 \leq X_{3} \leq 3
\end{aligned}
$$

where $X_{1}, X_{2}$ and $X_{3}$ are the variables of AA/Ch molar ratio; $N, N^{\prime}$-methylenebisacrylamide concentration (wt \%) and ammonium persulfate concentration (wt \%), respectively; $W_{X_{1}}, W_{X_{2}}$, and $W_{X_{3}}$ are the uncertainty of the tested variables; $V C_{T}, V C_{1}, V C_{2}$, and $V C_{3}$ are the total variable cost, and the individual variable cost of $\mathrm{AA}, N, N^{\prime}$-methylenebisacrylamide, and ammonium persulfate, respectively, in USD $/ \mathrm{kg}$; $A, I$ and $C$ are the computed material usage for AA, $N, N^{\prime}$-methylenebisacrylamide, and ammonium persulfate in $\mathrm{g}$.

\subsubsection{Case 1: Absorbent Material}

To determine the upper boundary limits of the swelling capacity and total variable cost of the Ch-graft-PA absorbent material, the set objective function for the summation of Equations (13) and (14) were maximized. This is subject to the constraints in Equations (15)-(27) that must be satisfied. Results indicated a swelling capacity at a global maximum of $354 \mathrm{~g} / \mathrm{g}$ and a $10 \mathrm{~g} / \mathrm{g}$ cumulative error of uncertainty. This is under the parametric conditions of $10 \mathrm{AA} / \mathrm{Ch}$ molar ratio, $1.0 \mathrm{wt} \%$ $N, N^{\prime}$-methylenebisacrylamide, and $3.0 \mathrm{wt} \%$ ammonium persulfate with an associated total variable cost of $16.5 \mathrm{USD} / \mathrm{kg}$.

A separate objective function was set to determine the lower boundary limits of the swelling capacity and total variable cost. Equation (18) is minimized under the established conditions of Equations (13)-(17) and (19)-(27). The results of the minimum swelling capacity (165 g/g) and total variable cost $(8.5 \mathrm{USD} / \mathrm{kg})$ were obtained in the parameters of $5 \mathrm{AA} / \mathrm{Ch}$ molar ratio, $1.0 \mathrm{wt} \%$ $\mathrm{N}, \mathrm{N}^{\prime}$-methylenebisacrylamide, and $1.0 \mathrm{wt} \%$ ammonium persulfate. Furthermore, its cumulative error of uncertainty reached $21 \mathrm{~g} / \mathrm{g}$. 
Figure 3a depicts the graphical representation of the Pareto optimality analysis that identified the appropriate boundary limits through determining the maximum swelling capacity at the least possible cost for the material synthesis of Ch-graft-PA absorbent. Results from the Pareto analysis revealed that large swelling capacities incurred higher variable cost. The swelling capacity is characterized by the amount of absorbed water and absorption rate [56]. Synthesizing absorbents with large swelling capacities are favorable to function as a superabsorbent polymer. Typically, the preparation of an AA based superabsorbent utilizes the initiator and crosslinker that contributes to higher production cost [49]. Higher AA/Ch molar ratio and ammonium persulfate concentration facilitate more carboxylic groups that initiate additional sites for crosslinking reaction, while lower $N, N^{\prime}$-methylenebisacrylamide concentration would avoid an extensive crosslinking to favorably increase the swelling characteristic [27]. Thus, a proper compromise between a high swelling capacity and a low variable cost is noteworthy for further investigation.
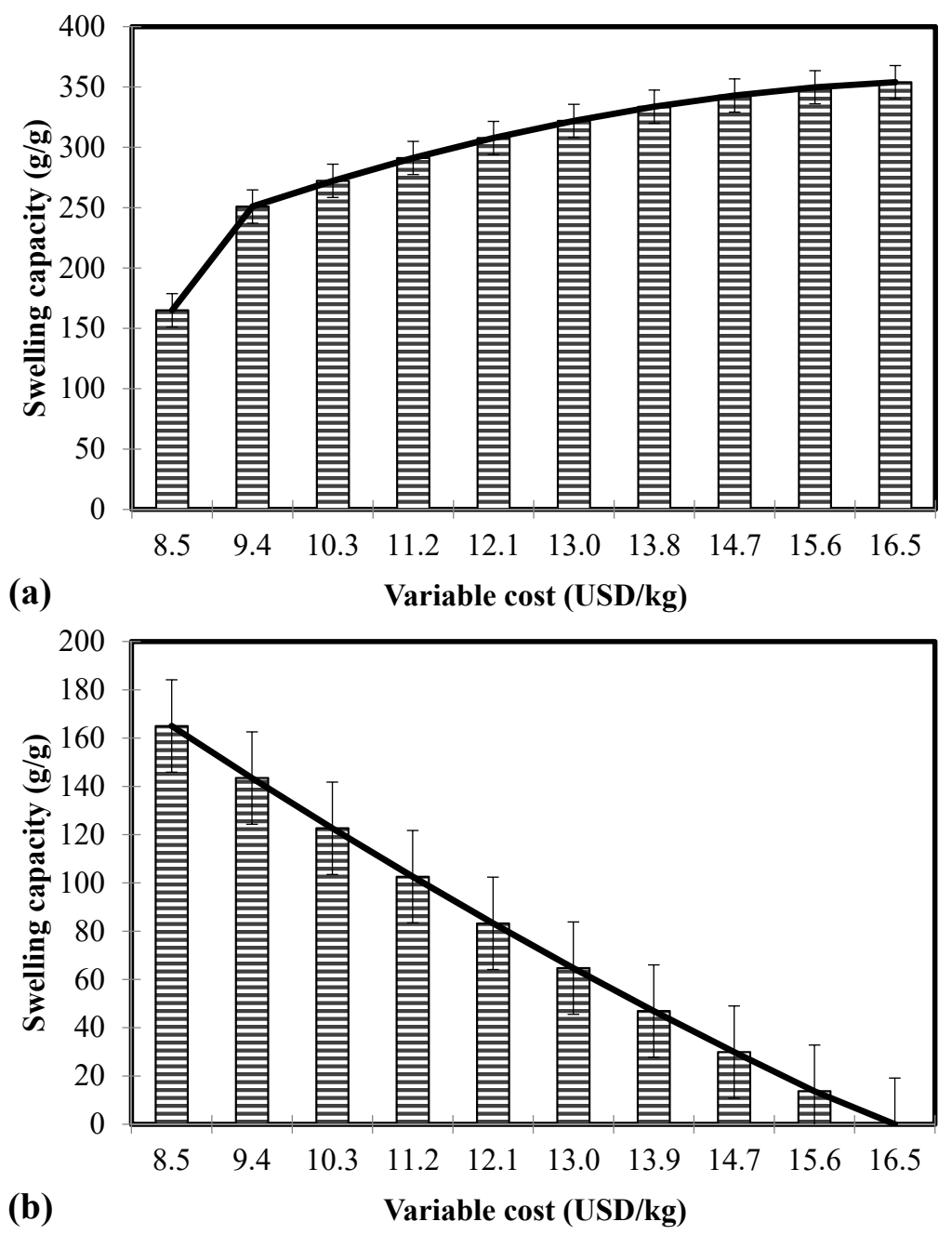

Figure 3. Pareto plot of variable cost with (a) maximum and (b) minimum conditions on the swelling capacity.

\subsubsection{Case 2: Adsorbent Material}

The sum of Equations (13) and (14) are minimized subject to the constraints in Equations (15)-(27) to appropriately establish the lower bound of the swelling capacity according to the desired functionality of the adsorbent material. Results for the global minimum value showed a non-swelling material that has a total variable cost of $16.5 \mathrm{USD} / \mathrm{kg}$ (upper bound for the total variable cost). The parametric conditions ensued five AA/Ch molar ratio, $3.0 \mathrm{wt} \% \mathrm{~N}, \mathrm{~N}^{\prime}$-methylenebisacrylamide and $1.0 \mathrm{wt} \%$ 
ammonium persulfate. Furthermore, the cumulative error of uncertainty in the swelling capacity reached $18 \mathrm{~g} / \mathrm{g}$.

On the other hand, the objective function in Equation (18) is minimized under the conditions of Equations (13)-(17) and (19)-(27). This resulted to an upper boundary limit of the swelling capacity at $165 \mathrm{~g} / \mathrm{g}$ (with a $21 \mathrm{~g} / \mathrm{g}$ cumulative uncertainty of results) and a lower boundary limit of the total variable cost at $8.5 \mathrm{USD} / \mathrm{kg}$ for the synthesis of Ch-graft-PA adsorbent. The variables of acid/Ch molar ratio, $N, N^{\prime}$-methylenebisacrylamide concentration and ammonium persulfate concentration rendered values of 5.0, $1.0 \mathrm{wt} \%$, and $1.0 \mathrm{wt} \%$, respectively.

The results of the Pareto set that comprise the boundary limits to appropriately synthesize the adsorbent material according to its desired minimum swelling capacity and variable cost are depicted in Figure $3 \mathrm{~b}$. In adsorption processes, high swelling materials have the capacity to adsorb large quantities of water molecules that increases the volume of the adsorbent. This would consequently lead to fouling and a sudden stop in the flow of wastewater in the column after a fixed amount of time [38]. It is thus desirable for adsorbents to have a low swelling capacity to be able to capitalize on the material in industrial applications. However, it was revealed in the results that a lower swelling characteristic incurs a higher total variable cost in the Pareto analysis. This is attributed to a higher material usage of the $N, N^{\prime}$-methylenebisacrylamide to lower the swelling capacity due to extensive crosslinking in the adsorbent synthesis [27]. Therefore, an investigation in a multi-objective optimization using the fuzzy logic approach is essential for a decision making analysis.

\subsection{Multi-Objective Fuzzy Optimization Result}

In order to optimize the objective function and the constraints, a decision in a fuzzy environment is required through the analogy of nonfuzzy environments as to select the activities that enables to simultaneously satisfy the objective function and constraints [57]. Based on the functionality of the polymer clay nanocomposite material, the fuzzy optimization was utilized for the decision making strategy of the two case studies presented in this research. The main objective function in Equation (28) is carried out in a global optimization procedure under the interval of 0 (dissatisfied) to 1 (satisfied) of the overall satisfaction rating $\left(\mu_{O}\right)$ in Equation (29). The multi-objective fuzzy optimization process also included the constraints in Equations (13)-(27).

$$
\begin{gathered}
\mu_{O} \leq \mu_{S C} \& \mu_{V C} \\
0 \leq \mu_{O} \leq 1
\end{gathered}
$$

In order to reach the fuzzy goal of the synthesis of an absorbent material (Case 1), the fuzzy constraints are subject to the constraints on the maximum swelling capacity $\left(\mu_{S C}\right)$ and minimum variable cost $\left(\mu_{V C}\right)$ in Equations (30) and (31), respectively.

$$
\begin{aligned}
\mu_{S C} & =\frac{Y_{Q}-185.58}{178.23} \\
\mu_{V C} & =\frac{16.47-V C_{T}}{7.96}
\end{aligned}
$$

For the adsorbent synthesis (Case 2), the fuzzy goal is attained with the minimized fuzzy constraints of the overall swelling capacity (Equation (32)) and total variable cost (Equation (33)).

$$
\begin{aligned}
& \mu_{S C}=\frac{185.58-Y_{Q}}{168.69} \\
& \mu_{V C}=\frac{16.49-V C_{T}}{7.94}
\end{aligned}
$$

The fuzzy objective function and its constraints are characterized by its membership function. Specifically, the linear membership function can facilitate the estimation of non-linear equations 
and is favorable to define the subjective preference of any objective uncertainty [58]. In a graphical representation, the linear membership function can be either maximized (Figure 4a) or minimized (Figure $4 \mathrm{~b}$ ) according to its objective function. Moreover, the boundary limits utilized in the fuzzy optimization for the swelling capacity and variable cost are derived from the Pareto analysis described in the preceding section. The boundary limits for absorbent synthesis (Case 1) are as follows: (1) overall swelling capacity of $364 \mathrm{~g} / \mathrm{g}$ (upper), (2) overall swelling capacity of $186 \mathrm{~g} / \mathrm{g}$ (lower), (3) total variable cost of $16.5 \mathrm{USD} / \mathrm{kg}$ (upper), and (4) total variable cost of $8.5 \mathrm{USD} / \mathrm{kg}$ (lower). For adsorbent synthesis (Case 2), the boundary limits are as follows: (1) overall swelling capacity of $186 \mathrm{~g} / \mathrm{g}$ (upper), (2) overall swelling capacity of $17 \mathrm{~g} / \mathrm{g}$ (lower), (3) total variable cost of $16.5 \mathrm{USD} / \mathrm{kg}$ (upper), and (4) total variable cost of $8.5 \mathrm{USD} / \mathrm{kg}$ (lower).

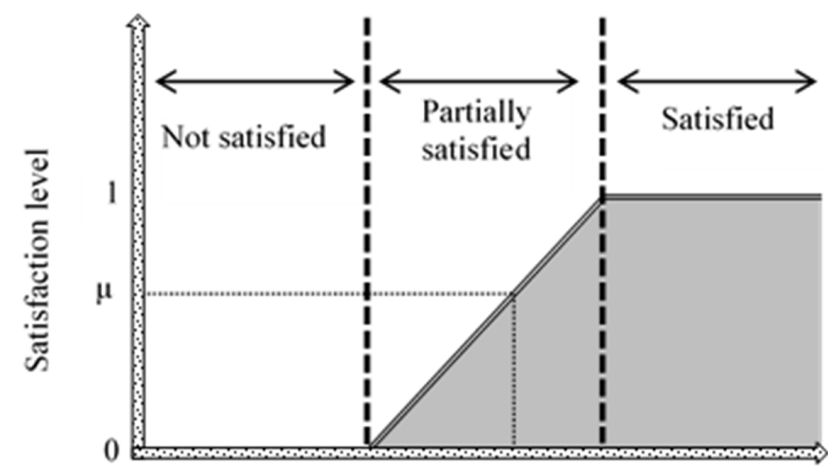

Objective function: Maximization

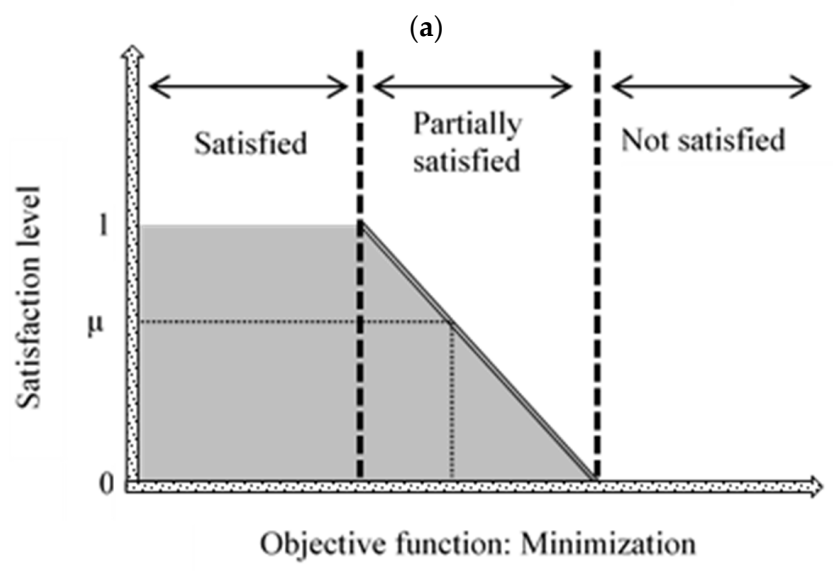

(b)

Figure 4. Linear membership function at goals towards (a) maximization and (b) minimization.

The fuzzy global optimal results from the clay-polymer composite material synthesis are listed in Table 3. Results showed that the maximum $\lambda_{O}$ values for the absorbent and adsorbent material were 0.672 and 0.523 , respectively. This indicates that the material synthesis upon the various matrix of $\mathrm{AA} / \mathrm{Ch}$ molar ratio, $N, N^{\prime}$-methylenebisacrylamide concentration, and ammonium persulfate concentration were able to successfully reach a compromise solution for the absorbent and adsorbent synthesis with an aggregated satisfaction rating of $67.2 \%$ and $52.3 \%$, respectively.

For the absorbent synthesis (Case 1), a proper allocation scheme that achieves the fuzzy goal subjected to its fuzzy constraints reached an overall swelling capacity of $305 \mathrm{~g} / \mathrm{g}$ and a total variable cost of $10.8 \mathrm{USD} / \mathrm{kg}$. The solution that achieved the highest swelling capacity at the least possible cost corresponds to the fuzzy optimum conditions of $10.0 \mathrm{AA} / \mathrm{Ch}$ molar ratio, $1.0 \mathrm{wt} \%$ $N, N^{\prime}$-methylenebisacrylamide, and $1.6 \mathrm{wt} \%$ ammonium persulfate. The resulting solution is desirable for synthesizing a superabsorbent material with a high swelling capacity. Typically, superabsorbents are able to keep large quantity of water that are irremovable under pressure due to its loosely crosslinked 
hydrophilic characteristic as a polymer material. A high-level acid to polymer ratio, low-level crosslinker dose, and mid-level initiator dose are desirable to appropriately initiate a loose crosslinking reaction in the carboxylate groups. In comparison with the study of Abdel Aziz and Salama [27], the optimum results using the RSM model led to a swelling capacity of $351 \mathrm{~g} / \mathrm{g}$ (9.76 AA/Ch molar ratio, $1.04 \mathrm{wt}$ $\% \mathrm{~N}^{\prime}$-methylenebisacrylamide, and $2.98 \mathrm{wt} \%$ ammonium persulfate). However, the total variable cost for this synthesis is $16.6 \mathrm{USD} / \mathrm{kg}$ that is $53.7 \%$ more expensive than in the fuzzy optimal solution. Thus, fuzzy optimization was able to reach a compromise solution based on a desirable swelling capacity with a more economical cost for superabsorbent synthesis.

Table 3. Fuzzy optimal solutions based on different objectives for the synthesis of ChPA-Mt material.

\begin{tabular}{|c|c|c|c|}
\hline \multirow[b]{2}{*}{ Parameters } & \multirow[b]{2}{*}{ Unit } & \multicolumn{2}{|c|}{ Goal } \\
\hline & & $\begin{array}{c}\text { Absorbent } \\
(\uparrow): \text { Swelling Capacity } \\
(\downarrow): \text { Variable Cost }\end{array}$ & $\begin{array}{c}\text { Adsorben } \\
(\downarrow): \text { Swelling Capacity } \\
(\downarrow) \text { : Variable Cost }\end{array}$ \\
\hline$\mu_{O}$ & $\%$ & 67.2 & 52.3 \\
\hline$\mu_{S C}$ & $\%$ & 67.2 & 52.3 \\
\hline$\mu_{V C}$ & $\%$ & 67.2 & 52.3 \\
\hline Swelling capacity $\left(Y_{Q}\right)$ & $\mathrm{g} / \mathrm{g}$ & 2 & 78 \\
\hline Cumulative uncertainty $\left(W_{Y_{Q}}\right)$ & $\mathrm{g} / \mathrm{g}$ & 15 & 19 \\
\hline $\begin{array}{l}\text { Overall }\left(Y_{Q}+W_{Y_{Q}}\right) \\
\text { Costing: }\end{array}$ & $\mathrm{g} / \mathrm{g}$ & 305 & 97 \\
\hline Arylic acid & $\mathrm{USD} / \mathrm{kg}$ & 1.0 & 0.5 \\
\hline$N, N^{\prime}$-methylenebisacrylamide & $\mathrm{USD} / \mathrm{kg}$ & 4.1 & 8.0 \\
\hline Ammonium persulfate & $\mathrm{USD} / \mathrm{kg}$ & 5.7 & 3.8 \\
\hline Total variable cost & $\mathrm{USD} / \mathrm{kg}$ & 10.8 & 12.3 \\
\hline \multicolumn{4}{|l|}{ Process Parameters: } \\
\hline $\mathrm{AA} / \mathrm{Ch}$ & & 10.0 & 5.0 \\
\hline$N, N^{\prime}$-methylenebisacrylamide & wt $\%$ & 1.0 & 1.9 \\
\hline Ammonium persulfate & wt $\%$ & 1.6 & 1.0 \\
\hline
\end{tabular}

Conversely, materials in adsorption technology that exhibit a high swelling degree are highly unfavorable as adsorbents [38]. The adsorbent synthesis (Case 2) in the fuzzy-based decision making analysis revealed a minimum overall swelling capacity and total variable cost of $97 \mathrm{~g} / \mathrm{g}$ and $12.3 \mathrm{USD} / \mathrm{kg}$, respectively. The fuzzy optimum solution resulted in the parameters of $5.0 \mathrm{AA} / \mathrm{Ch}$ molar ratio, $1.9 \mathrm{wt} \%$ $N, N^{\prime}$-methylenebisacrylamide, and $1.0 \mathrm{wt} \%$ ammonium persulfate. This has been selected to reach a compromise solution by simultaneously minimizing the swelling capacity and its associated costs for synthesis. The acid to polymer ratio (low), crosslinker (mid), and initiator (low) combination are favorable due to promoting an extensive crosslinking reaction leading to smaller swelling capacity in the Ch-graft-PA material. This would ultimately satisfy the functionality of the adsorbent as the swelling characteristic is a crucial factor in adsorption technologies.

\section{Conclusions}

In this study, a strategic decision making analysis for synthesis of ChPA-Mt was investigated depending on its functionality as an absorbent or adsorbent. The tested variables of AA/Ch molar ratio, $N, N^{\prime}$-methylenebisacrylamide concentration, and ammonium persulfate concentration were studied in conjunction with an uncertainty analysis in the response (swelling capacity) and its associated variable cost. The Pareto set analysis indicated the lower to upper boundary limits for the two case studies as follows: (1) absorbent material, overall swelling capacity $(186 \mathrm{~g} / \mathrm{g}$ to $364 \mathrm{~g} / \mathrm{g})$ and total variable cost (8.5 USD $/ \mathrm{kg}$ to $16.5 \mathrm{USD} / \mathrm{kg}$ ); and (2) adsorbent material, overall swelling capacity ( $17 \mathrm{~g} / \mathrm{g}$ to $186 \mathrm{~g} / \mathrm{g}$ ) and total variable cost (8.5 USD $/ \mathrm{kg}$ to $16.5 \mathrm{USD} / \mathrm{kg}$ ). A multi-objective fuzzy optimization showed an innovative approach to determine a solution for the best condition in the material synthesis. According to its functionality, the absorbent material $(305 \mathrm{~g} / \mathrm{g}$ and $10.8 \mathrm{USD} / \mathrm{kg})$ and adsorbent material $(97 \mathrm{~g} / \mathrm{g}$ and 
$12.3 \mathrm{USD} / \mathrm{kg}$ ) showed a satisfaction rating in its synthesis of $67.2 \%$ and $52.3 \%$, respectively. Therefore, the application of the global fuzzy optimal solutions and its respective conditions in the case studies proves to be efficient in relation to the material synthesis. Furthermore, the incorporation of the criteria of the variable cost in terms of material usage and the cumulative uncertainty of the response have successfully ensued essential compromise results in the decision making process.

Author Contributions: Conceptualization, methodology, and analysis, A.E.S.C.; writing, reviewing, and editing, A.E.S.C and C.M.F.; supervision and funding acquisition, J.J.Y.

Acknowledgments: The authors would like to acknowledge the National Research Foundation of Korea through Ministry of Education (No. 2016R1A6A1A03012812) for the financial support of this research.

Conflicts of Interest: The authors declare no conflict of interest.

\section{References}

1. Zhang, J.; Wang, Q.; Wang, A. Synthesis and characterization of chitosan-g-poly(acrylic acid)/attapulgite superabsorbent composites. Carbohydr. Polym. 2007, 68, 367-374. [CrossRef]

2. Kabiri, K.; Roshanfekr, S. Converting water absorbent polymer to alcohol absorbent polymer. Polym. Adv. Technol. 2013, 24, 28-33. [CrossRef]

3. Ghazy, M.B.M.; El-Hai, F.A.; Mohamed, M.F.; Essawy, H.A. Potassium fulvate as co-interpenetrating agent during graft polymerization of acrylic acid from cellulose. Int. J. Biol. Macromol. 2016, 91, 1206-1214. [CrossRef] [PubMed]

4. Zheng, Y.; Hua, S.; Wang, A. Adsorption behavior of $\mathrm{Cu} 2+$ from aqueous solutions onto starch-g-poly (acrylic acid)/sodium humate hydrogels. Desalination 2010, 263, 170-175. [CrossRef]

5. Kabiri, K.; Omidian, H.; Hashemi, S.A.; Zohuriaan-Mehr, M.J. Synthesis of fast-swelling superabsorbent hydrogels: Effect of crosslinker type and concentration on porosity and absorption rate. Eur. Polym. J. 2003, 39, 1341-1348. [CrossRef]

6. Singh, J.; Dhaliwal, A.S. Synthesis, characterization and swelling behavior of silver nanoparticles containing superabsorbent based on grafted copolymer of polyacrylic acid/Guar gum. Vacuum 2018, 157, 51-60. [CrossRef]

7. Wang, W.; Wang, J.; Kang, Y.; Wang, A. Synthesis, swelling and responsive properties of a new composite hydrogel based on hydroxyethyl cellulose and medicinal stone. Compos. Part B Eng. 2011, 42, 809-818. [CrossRef]

8. Pourjavadi, A.; Fakoorpoor, S.M.; Hosseini, P.; Khaloo, A. Interactions between superabsorbent polymers and cement-based composites incorporating colloidal silica nanoparticles. Cem. Concr. Compos. 2013, 37, 196-204. [CrossRef]

9. Bao, Y.; Ma, J.; Li, N. Synthesis and swelling behaviors of sodium carboxymethyl cellulose-g-poly (AA-co-AM-co-AMPS)/MMT superabsorbent hydrogel. Carbohydr. Polym. 2011, 84, 76-82. [CrossRef]

10. Bhattacharyya, R.; Ray, S.K. Micro- and nano-sized bentonite filled composite superabsorbents of chitosan and acrylic copolymer for removal of synthetic dyes from water. Appl. Clay Sci. 2014, 101, 510-520. [CrossRef]

11. Fang, S.; Wang, G.; Li, P.; Xing, R.; Liu, S.; Qin, Y.; Yu, H.; Chen, X.; Li, K. Synthesis of chitosan derivative graft acrylic acid superabsorbent polymers and its application as water retaining agent. Int. J. Biol. Macromol. 2018, 115, 754-761. [CrossRef]

12. Gao, J.; Yang, Q.; Ran, F.; Ma, G.; Lei, Z. Preparation and properties of novel eco-friendly superabsorbent composites based on raw wheat bran and clays. Appl. Clay Sci. 2016, 132-133, 739-747. [CrossRef]

13. Da Costa, M.P.M.; De Mello Ferreira, I.L.; De Macedo Cruz, M.T. New polyelectrolyte complex from pectin/chitosan and montmorillonite clay. Carbohydr. Polym. 2016, 146, 123-130. [CrossRef]

14. Jayakumar, R.; Nagahama, H.; Furuike, T.; Tamura, H. Synthesis of phosphorylated chitosan by novel method and its characterization. Int. J. Biol. Macromol. 2008, 42, 335-339. [CrossRef]

15. Fazli, Y.; Shariatinia, Z. Controlled release of cefazolin sodium antibiotic drug from electrospun chitosan-polyethylene oxide nanofibrous Mats. Mater. Sci. Eng. C 2017, 71, 614-652. [CrossRef]

16. Wang, L.; Zhang, J; Wang, A. Removal of methylene blue from aqueous solution using chitosan- g-poly(acrylic acid)/montmorillonite superadsorbent nanocomposite. Colloids Surf. A Physicochem. Eng. Asp. 2008, 322, 47-53. [CrossRef] 
17. Je, J.Y.; Kim, S.K. Antimicrobial action of novel chitin derivative. Biochim. Biophys. Acta Gen. Subj. 2006, 1760, 104-109. [CrossRef]

18. Pelissari, F.M.; Yamashita, F.; Garcia, M.A.; Martino, M.N.; Zaritzky, N.E.; Grossmann, M.V.E. Constrained mixture design applied to the development of cassava starch-chitosan blown films. J. Food Eng. 2012, 108, 262-267. [CrossRef]

19. Gao, X.; Cao, Y.; Song, X.; Zhang, Z.; Zhuang, X.; He, C.; Chen, X. Biodegradable, pH-responsive carboxymethyl cellulose/poly(acrylic acid) hydrogels for oral insulin delivery. Macromol. Biosci. 2014, 14, 565-575. [CrossRef]

20. Yadav, M.; Rhee, K.Y. Superabsorbent nanocomposite (alginate-g-PAMPS/MMT): Synthesis, characterization and swelling behavior. Carbohydr. Polym. 2012, 90, 165-173. [CrossRef]

21. Feng, E.; Ma, G.; Wu, Y.; Wang, H.; Lei, Z. Preparation and properties of organic-inorganic composite superabsorbent based on xanthan gum and loess. Carbohydr. Polym. 2014, 111, 463-468. [CrossRef] [PubMed]

22. Shi, X.; Wang, W.; Kang, Y.; Wang, A. Enhanced swelling properties of a novel sodium alginate-based superabsorbent composites: NaAlg-g-poly(NaA-co-St)/APT. J. Appl. Polym. Sci. 2012, 125, 1822-1832. [CrossRef]

23. Spagnol, C.; Rodrigues, F.H.A.; Pereira, A.G.B.; Fajardo, A.R.; Rubira, A.F.; Muniz, E.C. Superabsorbent hydrogel composite made of cellulose nanofibrils and chitosan-graft-poly(acrylic acid). Carbohydr. Polym. 2012, 87, 2038-2045. [CrossRef]

24. Murray, H.H. Overview-Clay mineral applications. Appl. Clay Sci. 1991, 5, 379-395. [CrossRef]

25. Kotal, M.; Bhowmick, A.K. Polymer nanocomposites from modified clays: Recent advances and challenges. Prog. Polym. Sci. 2015, 51, 127-187. [CrossRef]

26. Mansoori, Y.; Atghia, S.V.; Zamanloo, M.R.; Imanzadeh, G.; Sirousazar, M. Polymer-clay nanocomposites: Free-radical grafting of polyacrylamide onto organophilic montmorillonite. Eur. Polym. J. 2010, 9, 1844-1853. [CrossRef]

27. Abdel Aziz, M.S.; Salama, H.E. Effect of vinyl montmorillonite on the physical, responsive and antimicrobial properties of the optimized polyacrylic acid/chitosan superabsorbent via Box-Behnken model. Int. J. Biol. Macromol. 2018, 116, 840-848. [CrossRef]

28. Nie, X.; Adalati, A.; Du, J.; Liu, H.; Xu, S.; Wang, J. Preparation of amphoteric nanocomposite hydrogels based on the exfoliation of montmorillonite via in-situ intercalative polymerization of hydrophilic cationic and anionic monomers. Appl. Clay Sci. 2014, 97, 132-137. [CrossRef]

29. Oyekanmi, A.A.; Ahmad, A.; Hossain, K.; Rafatullah, M. Statistical optimization for adsorption of Rhodamine B dye from aqueous solutions. J. Mol. Liq. 2019, 281, 48-58. [CrossRef]

30. Singh, K.P.; Gupta, S.; Singh, A.K.; Sinha, S. Optimizing adsorption of crystal violet dye from water by magnetic nanocomposite using response surface modeling approach. J. Hazard. Mater. 2011, 186, 1462-1473. [CrossRef]

31. Bezerra, M.A.; Santelli, R.E.; Oliveira, E.P.; Villar, L.S.; Escaleira, L.A. Response surface methodology (RSM) as a tool for optimization in analytical chemistry. Talanta 2008, 76, 965-977. [CrossRef] [PubMed]

32. Metternicht, G.; Gonzalez, S. FUERO: Foundations of a fuzzy exploratory model for soil erosion hazard prediction. Environ. Model. Softw. 2005, 20, 715-728. [CrossRef]

33. Jiang, H.; Eastman, J.R. Application of fuzzy measures in multi-criteria evaluation in GIS. Int. J. Geogr. Inf. Sci. 2000, 14, 173-184. [CrossRef]

34. Kangas, A.; Kangas, J.; Laukkanen, S. Fuzzy multicriteria approval method and its application to two forest planning problems. For. Sci. 2006, 52, 232-242.

35. Nagarpita, M.V.; Roy, P.; Shruthi, S.B.; Sailaja, R.R.N. Synthesis and swelling characteristics of chitosan and CMC grafted sodium acrylate-co-acrylamide using modified nanoclay and examining its efficacy for removal of dyes. Int. J. Biol. Macromol. 2017, 102, 1226-1240. [CrossRef] [PubMed]

36. Zhao, Y.; Chen, Y.; Zhao, J.; Tong, Z.; Jin, S. Preparation of SA-g-(PAA-co-PDMC) polyampholytic superabsorbent polymer and its application to the anionic dye adsorption removal from effluents. Sep. Purif. Technol. 2017, 188, 329-340. [CrossRef]

37. Shah, L.A.; Khan, M.; Javed, R.; Sayed, M.; Khan, M.S.; Khan, A.; Ullah, M. Superabsorbent polymer hydrogels with good thermal and mechanical properties for removal of selected heavy metal ions. J. Clean. Prod. 2018, 201, 78-87. [CrossRef] 
38. Kyzas, G.Z.; Kostoglou, M. Swelling-Adsorption interactions during mercury and nickel ions removal by chitosan derivatives. Sep. Purif. Technol. 2015, 149, 92-102. [CrossRef]

39. Naguib, H.F.; Abdel Aziz, M.S.; Saad, G.R. Synthesis, Characterization, and Microbial Activity of Nanocomposites of Chitosan-Graft-Poly(4-vinyl pyridine) Copolymer/Organophilic Montmorillonite. Polym. Plast. Technol. Eng. 2015, 54, 1270-1279. [CrossRef]

40. Zhang, F.; Cheng, J. Verification of fuzzy UML models with fuzzy Description Logic. Appl. Soft Comput. J. 2018, 73, 134-152. [CrossRef]

41. Pirouzan, D.; Yahyaei, M.; Banisi, S. Pareto based optimization of flotation cells configuration using an oriented genetic algorithm. Int. J. Miner. Process. 2014, 126, 107-116. [CrossRef]

42. Aviso, K.B.; Tan, R.R.; Culaba, A.B.; Cruz, J.B. Bi-level fuzzy optimization approach for water exchange in eco-industrial parks. Process Saf. Environ. Prot. 2010, 88, 31-40. [CrossRef]

43. Zimmermann, H.J. Fuzzy programming and linear programming with several objective functions. Fuzzy Sets Syst. 1978, 1, 45-55. [CrossRef]

44. Zimmermann, H.J. Fuzzy mathematical programming. Comput. Oper. Res. 1983, 10, 291-298. [CrossRef]

45. Czogala, E.; Zimmermann, H.-J. Decision making in uncertain environments. Eur. J. Oper. Res. 1986, 23, 202-212. [CrossRef]

46. Aviso, K.B.; Tan, R.R.; Culaba, A.B. Designing eco-industrial water exchange networks using fuzzy mathematical programming. Clean Technol. Environ. Policy 2010, 12, 353-363. [CrossRef]

47. Tapia, J.F.D.; Tan, R.R. Fuzzy optimization of multi-period carbon capture and storage systems with parametric uncertainties. Process Saf. Environ. Prot. 2014, 92, 545-554. [CrossRef]

48. Choi, A.E.S.; Roces, S.; Dugos, N.; Wan, M.W. Operating cost study through a Pareto-optimal fuzzy analysis using commercial ferrate (VI) in an ultrasound-assisted oxidative desulfurization of model sulfur compounds. Clean Technol. Environ. Policy 2016, 18, 1433-1441. [CrossRef]

49. Ge, H.; Wang, S. Thermal preparation of chitosan-acrylic acid superabsorbent: Optimization, characteristic and water absorbency. Carbohydr. Polym. 2014, 113, 296-303. [CrossRef]

50. Bukhari, S.M.H.; Khan, S.; Rehanullah, M.; Ranjha, N.M. Synthesis and Characterization of Chemically Cross-Linked Acrylic Acid/Gelatin Hydrogels: Effect of $\mathrm{pH}$ and Composition on Swelling and Drug Release. Int. J. Polym. Sci. 2015, 2015, 187961. [CrossRef]

51. Grisdanurak, N.; Akewaranugulsiri, S.; Futalan, C.M.; Tsai, W.; Kan, C.; Hsu, C.; Wan, M. The Study of Copper Adsorption from Aqueous Solution Using Crosslinked Chitosan Immobilized on Bentonite. J. Appl. Polym. Sci. 2012, 125, E132-E142. [CrossRef]

52. Kumar, P.; Kundu, P.P. Formation of semi-IPN membrane composed of crosslinked SPS-[PVdF-co-HFP/Nafion] for application in DMFC: A fine tuning between crosslinker and initiator. Mater. Chem. Phys. 2015, 164, 188-197. [CrossRef]

53. Wang, W.; Yu, Y.; Wang, P.; Wang, Q.; Li, Y.; Yuan, J.; Fan, X. Controlled graft polymerization on the surface of filter paper via enzyme-initiated RAFT polymerization. Carbohydr. Polym. 2019, 207, 239-245. [CrossRef] [PubMed]

54. Singhal, R.; Tomar, R.S.; Nagpal, A.K. Effect of cross-linker and initiator concentration on the swelling behaviour and network parameters of superabsorbent hydrogels based on acrylamide and acrylic acid. Int. J. Plast. Technol. 2009, 13, 22-37. [CrossRef]

55. Lim, S.; Zhu, J. Integrated data envelopment analysis: Global vs. local optimum. Eur. J. Oper. Res. 2013, 229, 276-278. [CrossRef]

56. Omidian, H.; Hashemi, S.A.; Sammes, P.G.; Meldrum, I. A model for the swelling of superabsorbent polymers. Polymer 1998, 39, 6697-6704. [CrossRef]

57. Zimmermann, H.-J. Individual Decision Making in Fuzzy Environments. In Fuzzy Sets, Decision Making, and Expert Systems; Springer: Dordrecht, The Netherlands, 1987; pp. 15-44. ISBN 978-0-89838-149-8.

58. Wen, B.; Li, H. An approach to formulation of FNLP with complex piecewise linear membership functions. Chin. J. Chem. Eng. 2014, 22, 411-417. [CrossRef]

(C) 2019 by the authors. Licensee MDPI, Basel, Switzerland. This article is an open access article distributed under the terms and conditions of the Creative Commons Attribution (CC BY) license (http://creativecommons.org/licenses/by/4.0/). 